\title{
Follicular carcinoma of the thyroid with aggressive metastatic behavior in a pregnant woman: Report of a case and review of the literature
}

\author{
Luciana Parlea, Lisa Fahim, David Munoz, Amir Hanna, Jennifer Anderson, \\ Michael Cusimano, Kalman Kovacs, Geoffrey Gardiner
}

Departments of Medicine (LP, AH), Laboratory Medicine, (LF, DM, KK, GG), and Surgery (JA, MC) at St. Michael's Hospital, University of Toronto, Toronto, ON, Canada

\begin{abstract}
Distant metastases as initial presentation of follicular carcinoma of the thyroid is rare, especially in young patients. We report the clinical and pathological features of a 33-year old pregnant patient with follicular carcinoma of the thyroid who presented with widespread bone and lung metastases at the time of diagnosis. The resected tumor had a focal insular component that showed extensive vascular invasion spreading beyond the thyroid capsule, and was associated with widespread bone and lung metastases. Despite its aggressive behavior, the tumor had low mitotic activity and Ki-67 nuclear labeling index. Tumor cells showed high microvascular density and down-regulation of E-cadherin, a calcium-dependent trans-membrane epithelial protein molecule known to promote intercellular adhesion. We suggest that architectural differentiation of the tumor and cell proliferation rate are not reliable markers of metastatic behavior in this particular thyroid neoplasm. Microvascular density and down-regulation of E-cadherin expression in the tumor should be included among histologic hallmarks of metastatic potential. The role of pregnancy in the aggressive behavior of this tumor is discussed along with a literature review.
\end{abstract}

Key words: Follicular carcinoma, Thyroid, Metastases, Pregnancy, Histology and Immunohistochemistry

\section{INTRODUCTION}

Follicular thyroid carcinoma is the second most common thyroid cancer after papillary carcinoma.

Address correspondence and requests for reprints to:

Dr. G. Gardiner, Department of Lab Medicine, St. Michael's

Hospital, 30 Bond Street, Toronto, ON M5B 1W8, 416-360-

4000, e-mail: gardinerg@smh.toronto.on.ca

Received 25-07-06, Revised 01-09-06, Accepted 05-09-06
It accounts for $10-20 \%$ of all thyroid malignancies and is most often seen in patients over forty years of age. ${ }^{1}$ The tumor usually presents as an asymptomatic solitary intrathyroid nodule. These neoplasms tend to metastasize hematogeneously, with lung and bone most commonly affected. While distant metastases at the time of diagnosis are reported in $11-20 \%$ of patients, ${ }^{2}$ less than $1 \%$ of these cases are seen in patients younger than 45 years of age. ${ }^{3}$ There have been 
a few case reports of follicular carcinoma causing unusual bony metastases, such as skull, ${ }^{4}$ mandible, ${ }^{5}$ maxilla, ${ }^{6}$ spine, ${ }^{7}$ and orbit. ${ }^{8}$ Synchronous lung metastasis in follicular carcinoma have been reported in about $20 \%$ of cases, with a mean age at presentation of over fifty. ${ }^{9}$ To our knowledge, there have been no case reports of a follicular thyroid cancer presenting with synchronous metastases diffusely affecting bone and lung at initial presentation in a young pregnant patient.

We discuss the unusual presentation of this case and its difficult management. We also explore the potential role of pregnancy in this patient's presentation and the pathology of this thyroid neoplasm relevant to metastasis.

\section{PATIENT'S DESCRIPTION}

A 33-year old Ethiopian woman, living in Canada for four years, presented at 34 weeks gestation with a one-month history of left hemiparesis and an enlarging right-sided fronto-parietal mass. The patient had been aware of a goiter for at least ten years. Her thyroid function tests were previously normal. She had noticed a small swelling in the right fronto-parietal region two months prior to becoming pregnant. Both the head mass and her goiter increased in size during pregnancy, particularly in the three months preceding her presentation. At the beginning of the third trimester she developed left hemiparesis and sought medical attention. A head CT scan showed a right fronto-parietal mass lesion that eroded through the skull causing cortical compression. This mass was initially thought to represent a meningioma. Obstetrical and neurosurgical consultations were obtained. The patient was managed initially with high doses of glucocorticoids which reduced her weakness. A Cesarean section and craniotomy were scheduled after two weeks to allow for further fetal development, given that the patient's neurological status was stable.

Pre-operative evaluation revealed the patient to be in no apparent distress, with stable vital signs except a heart rate of 114 . She had a large $7 \mathrm{~cm}$ right fronto-parietal mass and a very large goitre with retrosternal extension. Power testing showed 3/5 power in the upper left extremity, with otherwise normal neurological examination. She also had localized tenderness in her proximal left humerus.

The neck MRI showed a large right-sided thyroid mass extending inferiorly into the mediastinum, causing a left shift of the trachea but no compression (Figure 1A). There was also a separate mass arising from the anterior mediastinum and extending anteriorly and superiorly. A radiograph of the left shoulder showed destruction of the proximal part of the humerus. Free T4 was 5.2pmol/L (7.5-20.0), free $\mathrm{T} 3$ was $10.5 \mathrm{pmol} / \mathrm{L}$ (3.8-6.0), and TSH was $0.21 \mathrm{mU} / \mathrm{L}$ (0.40-5.5), consistent with T3 thyrotoxicosis.

Following Caesarian delivery of a healthy baby girl at 35 weeks gestation, further workup was initiated. Biopsies of the fronto-parietal mass, anterior mediastinal mass, and right thyroid lobe all revealed follicular thyroid carcinoma. A CT scan of the head showed a large mass destroying the lateral right frontal bone and extending into the scalp and intracranially with other areas of lytic involvement in the skull (Figure 1B), right mandible, and left orbit. There were vertebral lytic lesions at multiple levels as well as a $5 \mathrm{~cm}$ soft tissue mass in the left ileum (Figure 1C). Bilateral lung nodules were identified, with the largest measuring $1.4 \mathrm{~cm}$.

Following vascular embolization of the head mass, the patient underwent a craniotomy with resection of the extra-dural tumor. Despite the pre-operative embolization, the mass was extremely vascular. The pathologic fracture of the left humerus was operatively repaired. She then underwent resection of the thyroid, manubrium, and bilaterally the heads of clavicles, and first and second ribs, following preoperative embolization of the thyroid and manubrium lesions. The manubrium lesion was also very vascular. The pathology of all the intraoperative specimens confirmed the diagnosis of follicular thyroid carcinoma.

Following post-operative recovery, a dose of 200 millicurries $(\mathrm{mCi})$ of radioactive iodine $\left({ }^{131} \mathrm{I}\right)$ was given after pretreatment with synthetic TSH (Thyrogen). She received external beam radiation therapy to her left humerus. A whole body iodine scan done ten days after the iodine treatment showed widespread uptake in the thyroid bed, right side of the skull, right shoulder, lower thoracic and lumbar spine, right and 

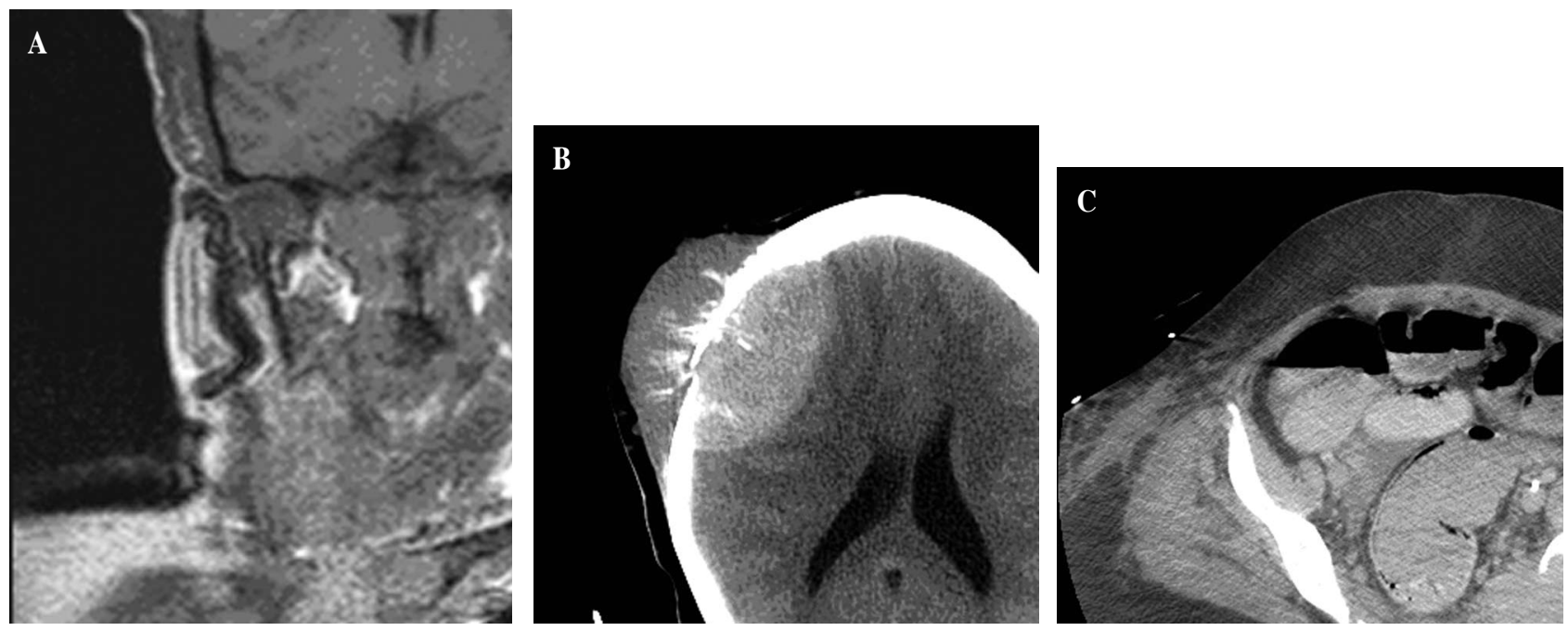

Figure 1. A. T1 weighted coronal MRI image showing a large right thyroid lobe mass extending into the mediastinum. B. CT head showing large fronto-parietal mass eroding through the skull, and extending into the scalp and intracranially. C. CT with contrast showing large $5.6 \times 5.0 \times 4.8 \mathrm{~cm}$ lesion extending across the L sacroiliac joint (arrow).

left hemipelvis, and left mid-to proximal femur. Her thyroglobulin level was elevated at $476.7 \mathrm{pmol} / \mathrm{L}$.

\section{PATHOLOGY}

The thyroid was enlarged with a nodular surface weighing 109 grams. On sectioning, there were multiple white-tan nodules ranging in size from 0.3 to 5 $\mathrm{cm}$ (Figure 2A). The resected cranium showed a 10 $\mathrm{x} 10.5 \mathrm{~cm}$ tan ill-defined tumor mass eroding through bone (Figure 2B). Histology of the thyroid tumor demonstrated colloid-containing follicles of varying sizes surrounded by a single layer of thyroid epithelial cells (Figure 3A) with small areas of solid growth pattern (insular component). There was extensive capsular and vascular tumoral invasion (Figure 3B).

Immunohistochemical staining with endothelial marker CD34 and factor 8 antigen demonstrated prominent microvascular density in the follicular neoplasm (25\% per unit surface area) (Figure 3C) compared to adjacent normal thyroid tissue (11\% per unit surface). Mitotic activity was less than 2 per 10 high power fields and proliferative marker Ki-67 nuclear labeling index was extremely low at $0.7 \%$ (Figure 3D). The scalp metastasis demonstrated the same follicular architecture as the primary (Figure 4). Thyroid epithelial cells at both sites were strongly immunopositive for thyroglobulin and thyroid tran- scription factor-1 (TTF-1) (Figure 4B). Immunostains for calcitonin, beta $\mathrm{HCG}$, estrogen receptor protein, and progesterone receptor protein were negative. Tumoral markers p53, Galectin 3, p27,
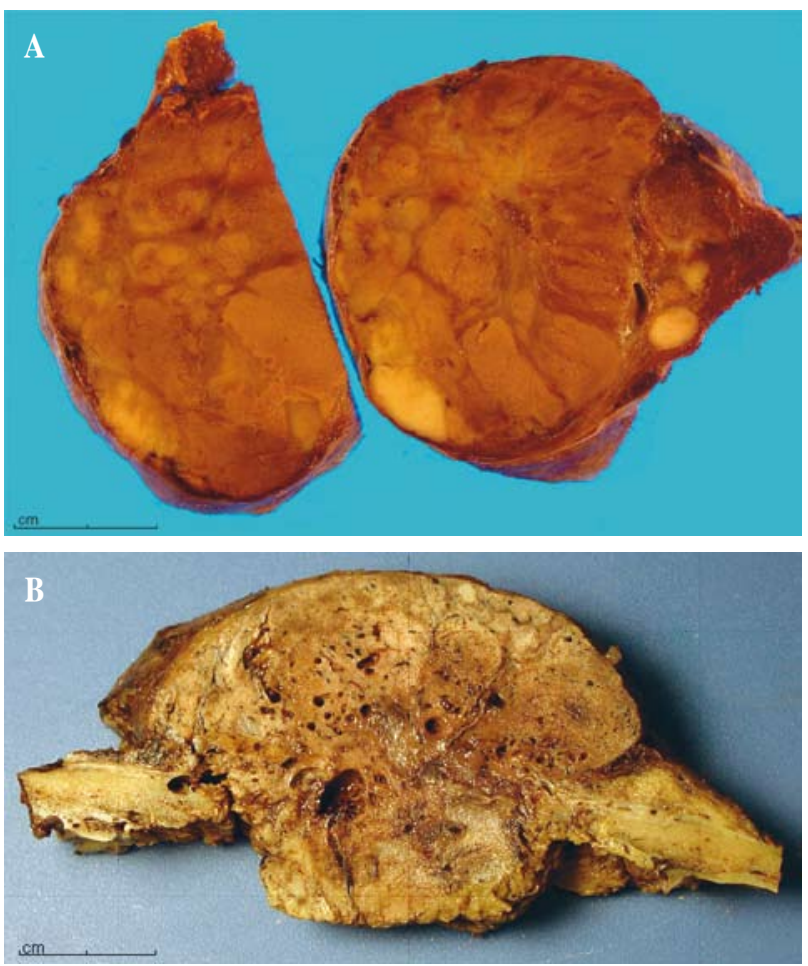

Figure 2. A. Gross pathology of the thyroid mass. B. Gross pathology of the scalp mass. 

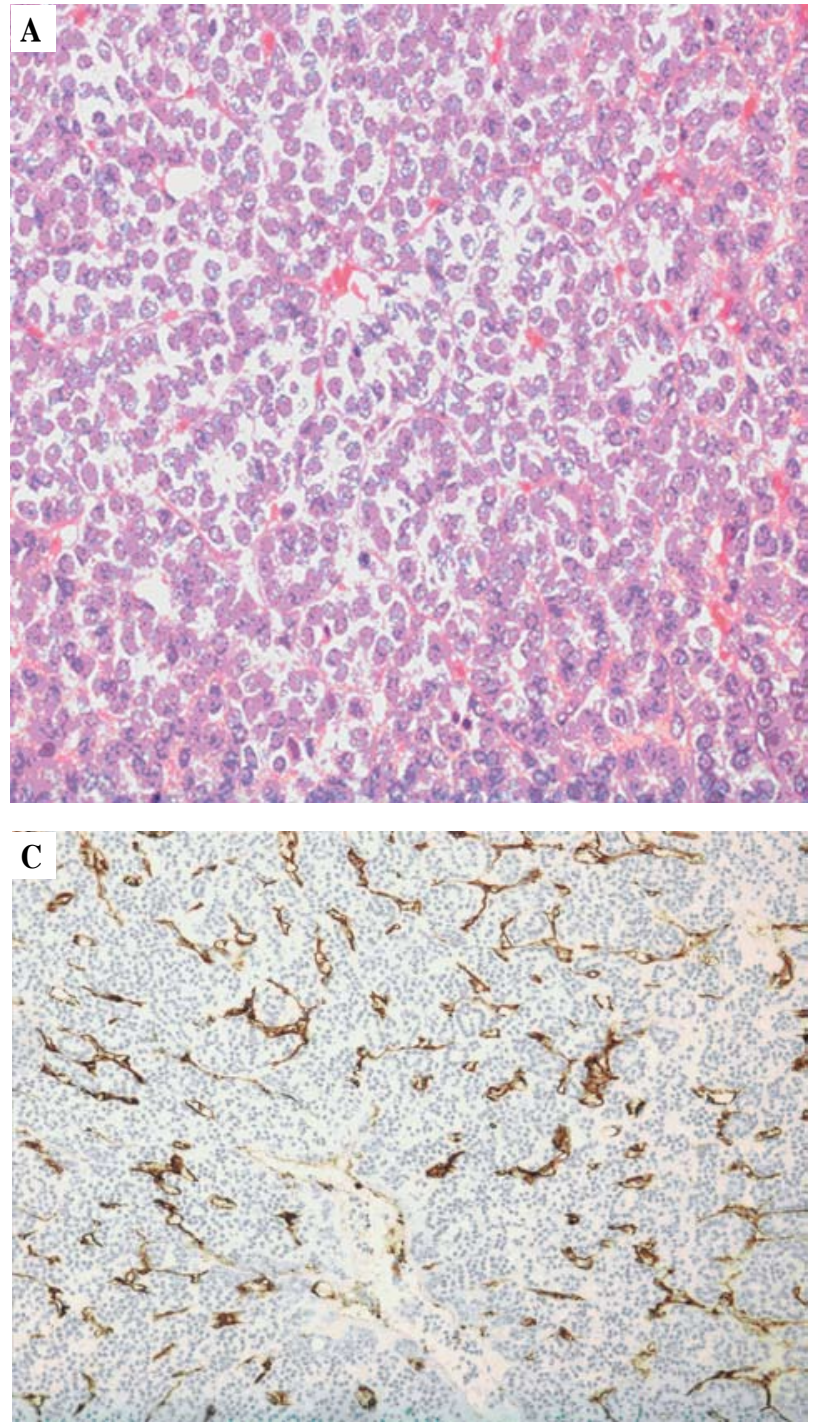

topoisomerase, and COX-2 were considered inconclusive. Less than $80 \%$ of tumor cells demonstrated cell membrane positivity for E-cadherin compared to normal thyroid, which had more than $95 \%$ membrane positivity.

\section{DISCUSSION}

Although the incidence of papillary thyroid carcinoma is much higher than of follicular carcinoma, the latter accounts for more deaths. ${ }^{10}$ Follicular carcinoma differs from papillary in that it occurs at an older age, exhibits hematogenous spread rather than lymphatic dissemination, and has a more aggressive behavior. ${ }^{11,12}$ Disseminated metastases from follicular carcinoma at the time of diagnosis in a young patient
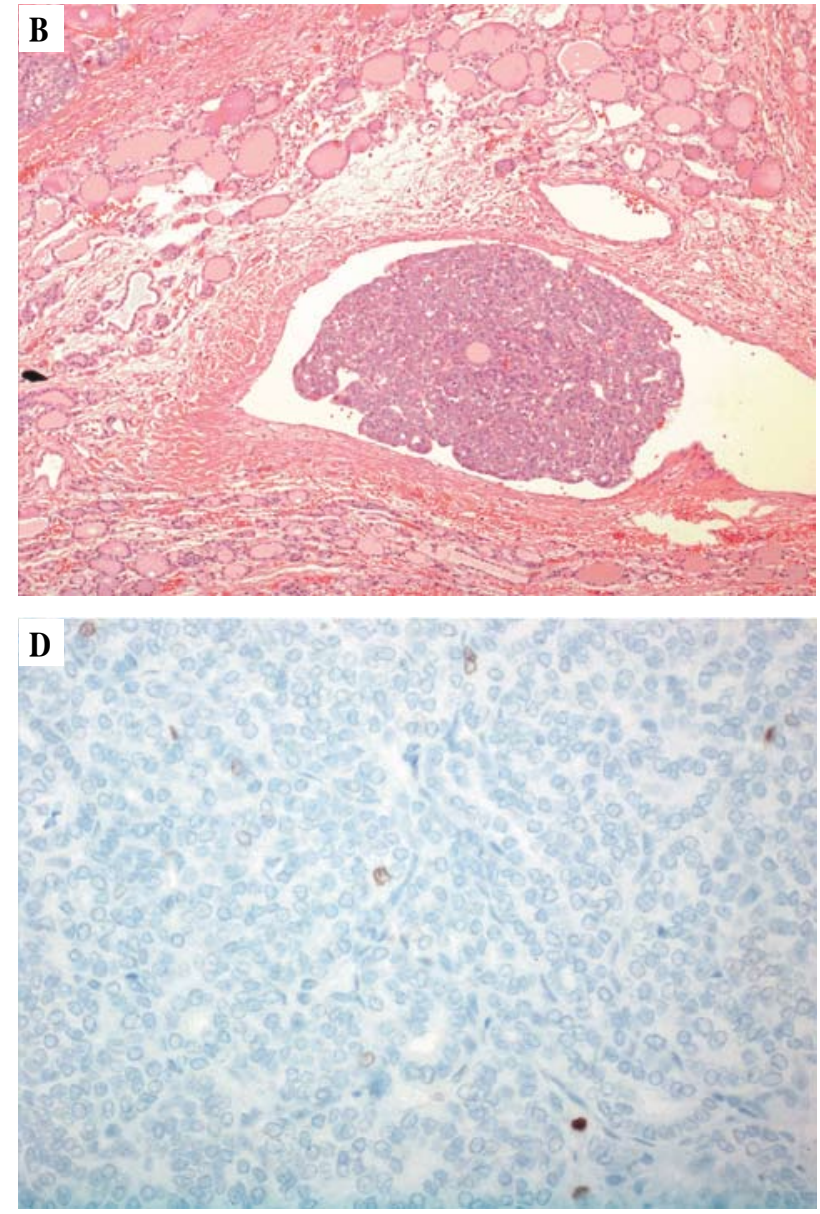

Figure 3. A. H\&E slide of the thyroid tumor shows follicular carcinoma. B. Extensive lymphovascular invasion of follicular carcinoma. C. CD 34 reactivity of thyroid tumor shows very prominent microvascular density. D. Tumor KI 67 activity indicates minimal cell proliferation.

remain exceedingly rare.

Thyroid carcinoma is the second most common malignancy diagnosed during pregnancy ${ }^{13}$ with breast cancer representing the first. Several studies have looked at the role of various reproductive and hormonal factors in the development and progression of thyroid carcinoma, yielding mixed results. Frequency of malignancy in thyroid nodules seems to be higher in pregnant women. ${ }^{14}$ Pregnancy may accelerate the progression of thyroid cancer, presumably via the role of human chorionic gonadotropin $(\beta-\mathrm{HCG})^{14-16}$ which can bind to the TSH receptor and stimulate tumor growth. Some authors support a link between parity and increased risk of thyroid cancer. ${ }^{14-16}$ Others, however, have observed only a 

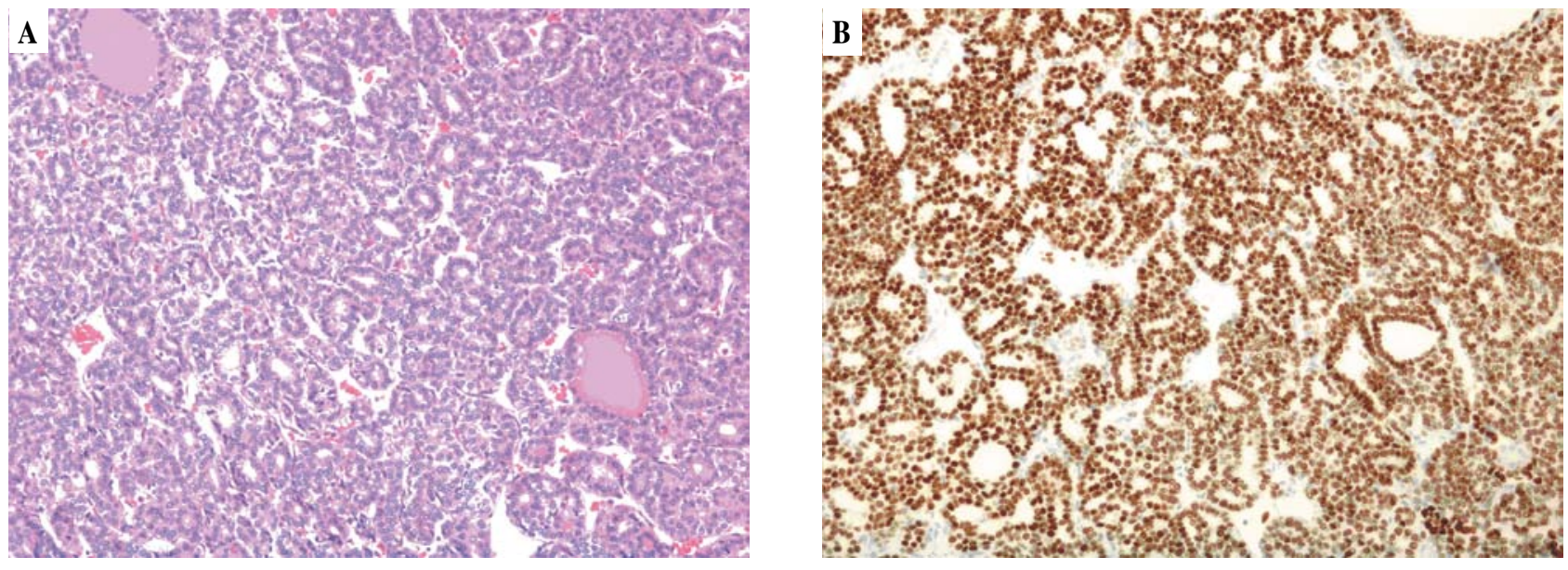

Figure 4. A. Scalp metastases of follicular carcinoma showing well differentiated epithelium-lined follicles. B. Immunoreactivity of scalp metastases to thyroid transcription factor 1 .

weak association ${ }^{17,18}$ or offer negative results. ${ }^{19-21}$ In a pooled analysis of 14 case controlled studies of thyroid carcinoma, Negri et $\mathrm{al}^{22}$ found a slightly increased risk of borderline significance in parous versus nulliparous women. In a subset analysis of follicular carcinoma (accounting for $14 \%$ of cases), the authors found a somewhat stronger association, particularly in women diagnosed at an age younger than 35. The prognosis of women diagnosed during pregnancy does not seem to differ from that of nonpregnant women, ${ }^{23-25}$ leading some authors to suggest that surgical treatment in thyroid cancer diagnosed late in pregnancy can be delayed until post delivery. ${ }^{23,24}$ However, most cancers seen in these studies were papillary and less than $3 \%$ of women presented with distant metastases. ${ }^{23,25}$

Of note, the tumor in this patient did not have estrogen, progesterone or $\beta$-HCG receptors identified. There is controversy regarding the presence of estrogen and progesterone receptors in thyroid malignancy. Some have found endogenous estrogen and estrogen binding receptors in thyroid tumors, ${ }^{26}$ while others have not been able to replicate these findings. ${ }^{27}$ The lack of $\beta$-HCG receptors in the tumor does not negate a role of $\beta$-HCG in stimulating this tumor via the TSH receptor. ${ }^{28}$

While pregnancy remains a plausible reason for this patient's aggressive presentation, another reason may be found in the tumor histology. Our case demonstrated many well known histologic parameters as- sociated with aggressive metastatic spread including focal insular growth pattern and widespread vascular invasion throughout the thyroid gland. Interestingly, tumor proliferation markers (mitotic count, Ki-67) were not increased in this case, a finding different from that of other studies. Nonetheless, a low proliferative activity would not preclude such a tumor from presenting at a late or advanced stage with distant metastases.

Tumor studies of microvascular density, i.e. the vascular bed of the neoplasms, have been shown to be a risk factor for dissemination, ${ }^{29}$ and this was readily apparent in our case with more than twice as many capillaries in the tumor as in adjacent normal thyroid tissue $(25 \%$ vs. $11 \%)$. Thyroid tumors in general are known to be more vascular than the normal thyroid gland and there is a correlation between vascular endothelial growth factor (VEGF) expression and more aggressive malignant behavior and metastasis. ${ }^{30}$ Microvascular density has also been shown to be increased in malignant follicular thyroid tumors, when compared with benign neoplasms. ${ }^{31}$

E-cadherin, a calcium dependent transmembrane epithelial protein that promotes intercellular adhesion, is usually expressed in normal follicular cells and follicular neoplasms including adenomas, carcinomas, and the follicular variant of papillary carcinoma. ${ }^{11}$ Recent studies have shown that downregulation of E-cadherin expression, defined as less than $90 \%$ of cells showing membrane positivity, is 
significantly associated with widely invasive growth, insular morphology, and a lesser degree of differentiation. ${ }^{32}$ The lack of E-cadherin expression is proposed as an independent prognostic factor for invasion by multivariate analysis. ${ }^{33,34}$ Our case showed less than $80 \%$ of cells expressing membrane positivity for E-cadherin.

Another point of significant debate was this patient's management. While the mainstay of treatment in follicular carcinoma of the thyroid is thyroidectomy followed by ${ }^{131} \mathrm{I}$ treatment, the course of action in such an advanced case in a young patient remains unclear. Young age is a very important positive prognostic factor for thyroid cancer. ${ }^{35-37}$ The presence of distant metastases at diagnosis considerably affects the survival; rates range from $82 \%$ at five years for distant metastases in patients younger than 45 years of age to as low as $34 \%$, depending on the prognostic system used. ${ }^{35}$ For patients presenting with synchronous distant metastases at the time of diagnosis of a differentiated thyroid cancer, overall survival rates have been estimated at $39 \%, 31 \%$, and $23 \%$ for 5,10 , and 15 years. ${ }^{36}$ Well differentiated tumor histology, younger age, radical surgery, and use of radioactive iodine were significant factors favoring survival. Metastases to more than one organ and follicular histology lead to a worse outcome. ${ }^{36}$ The location of this patient's metastases may also be a poor prognostic factor. Brown et al reported a $10 \mathrm{yr}$ survival of $54 \%$ in 20 patients with lung metastases, but there were $10 \mathrm{yr}$ survivors in 21 patients with skeletal metastases following treatment with ${ }^{131} \mathrm{I}^{38}$

Aggressive tumor debulking was performed in this case to decrease the amount of radioactive iodine needed. High doses of radioactive iodine have been linked to an increased risk of leukemia, bone, soft tissue, colorectal, and salivary gland cancers; ${ }^{39-42}$ some authors suggest that there exists a linear relationship between ${ }^{131}$ I dose and the risk of secondary cancer. Radiation pulmonary fibrosis in patients with pulmonary metastases after repeated ${ }^{131} \mathrm{I}$ doses is also a potential risk, ${ }^{43}$ albeit rarely reported.

In addition to thyroidectomy and ${ }^{131}$ I treatment, some authors support the use of external beam radiation therapy (EBRT) for both loco-regional control and control of inoperable metastases. ${ }^{44,45}$ The effectiveness of ${ }^{131} \mathrm{I}$ in bone metastases treatment is suboptimal. Even in patients who have bone metastases that take up ${ }^{131} \mathrm{I}$, a very small proportion are able to achieve complete response following ${ }^{131} \mathbf{I}$ therapy ${ }^{46}$. In particular, bone metastases associated with radiographic changes are known not to respond well to ${ }^{131}{ }^{2}{ }^{2,47}$ As such, our patient underwent EBRT to the large lytic area in her left humerus.

In summary, we present a rare case of a widely metastatic follicular carcinoma of the thyroid presenting in a pregnant woman. While an effect of pregnancy on the aggressiveness of the tumor is a possibility, the reason why this malignancy spread so readily may relate to its morphology. In addition to common histologic risk factors, microvascular density and reduced E-cadherin expression may be important pathologic parameters that contributed to metastatic potential. It can also be emphasized that this follicular carcinoma gave rise to distant metastases with low mitotic and Ki-67 indices. The current treatment limitations in the presence of widespread bone and lung metastasis have also been discussed.

\section{REFERENCES}

1. Mazzaferri EL, 1981 Papillary and follicular thyroid cancer: a selective approach to diagnosis and treatment. Annu Rev Med 32: 73-91.

2. Schlumberger M, Tubiana M, De Vathaire F, et al, 1986 Long-term results of treatment of 283 patients with lung and bone metastases from differentiated thyroid carcinoma. J Clin Endocrinol Metab 63: 960-967.

3. Shaha AR, Shah JP, Loree TR, 1997 Differentiated thyroid cancer presenting initially with distant metastasis. Am J Surg 174: 474-476.

4. Ozdemir N, Senoglu M, Acar UD, Canda MS, 2004 Skull metastasis of follicular thyroid carcinoma. Acta Neurochir (Wien) 146: 1155-1158.

5. Anil S, Lal PM, Gill DS, Beena VT, 1999 Metastasis of thyroid carcinoma to the mandible. Case report. Aust Dent J 44: 56-57.

6. Hefer T, Manor R, Zvi Joachims H, et al, 1998 Metastatic follicular thyroid carcinoma to the maxilla. J Laryngol Otol 112: 69-72.

7. Scarrow AM, Colina JL, Levy EI, Welch WC, 1999 Thyroid carcinoma with isolated spinal metastasis: case history and review of the literature. Clin Neurol Neurosurg 101: 245-248.

8. Daumerie C, De Potter P, Godfraind C, et al, 2000 Orbital metastasis as primary manifestation of thyroid carcinoma. Thyroid 10: 189-192. 
9. Lin JD, Chao TC, Hsueh C, 2004 Follicular thyroid carcinomas with lung metastases: a 23-year retrospective study. Endocr J 51: 219-225.

10. Grebe SK, Hay ID, 1995 Follicular thyroid cancer. Endocrinol Metab Clin North Am 24: 761-801.

11. Simoes M, Asa SL, Kroll TG, et al 2004 Follicular carcinoma. In: Delellis RA, Lloyd RV, Heitz PU and Eng $\mathrm{C}$ (eds) WHO classification of tumors, pathology and genetics of tumors of endocrine organs, IARC Press, Lyon; pp, 67-72.

12. Baloch ZW, Li Volsi V 2004 Pathology of thyroid and parathyroid disease. In: Mills SE (ed) Sternberg's surgical pathology 4th edition, Philadelphia; pp, 576-578.

13. Smith LH, Danielsen B, Allen ME, Cress R, 2003 Cancer associated with obstetric delivery: results of linkage with the California cancer registry. Am J Obstet Gynecol 189: 1128-1135.

14. Rosen IB, Walfish PG, 1986 Pregnancy as a predisposing factor in thyroid neoplasia. Arch Surg 121: 1287-1290.

15. Kobayashi K, Tanaka Y, Ishiguro S, Mori T, 1994 Rapidly growing thyroid carcinoma during pregnancy. J Surg Oncol 55: 61-64.

16. Foster HM, Sinha SN, 1988 Pregnancy and thyroid cancer -- two case reports and a review of the current literature. P N G Med J 31: 287-291.

17. Galanti MR, Lambe M, Ekbom A, Sparen P, Pettersson B, 1995 Parity and risk of thyroid cancer: a nested casecontrol study of a nationwide Swedish cohort. Cancer Causes Control 6: 37-44.

18. Kravdal O, Glattre E, Haldorsen T, 1991 Positive correlation between parity and incidence of thyroid cancer: new evidence based on complete Norwegian birth cohorts. Int J Cancer 49: 831-836.

19. Levi F, Franceschi S, Gulie C, Negri E, La Vecchia C, 1993 Female thyroid cancer: the role of reproductive and hormonal factors in Switzerland. Oncology 50: 309315.

20. Franceschi S, Fassina A, Talamini R, et al, 1990 The influence of reproductive and hormonal factors on thyroid cancer in women. Rev Epidemiol Sante Publique 38: 27-34.

21. Akslen LA, Nilssen S, Kvale G, 1992 Reproductive factors and risk of thyroid cancer. A prospective study of 63,090 women from Norway. Br J Cancer 65: 772-774.

22. Negri E, Dal Maso L, Ron E, et al, 1999 A pooled analysis of case-control studies of thyroid cancer. II. Menstrual and reproductive factors. Cancer Causes Control 10: 143-155.

23. Moosa M, Mazzaferri EL, 1997 Outcome of differentiated thyroid cancer diagnosed in pregnant women. J Clin Endocrinol Metab 82: 2862-2866.

24. Herzon FS, Morris DM, Segal MN, Rauch G, Parnell T, 1994 Coexistent thyroid cancer and pregnancy. Arch Otolaryngol Head Neck Surg 120: 1191-1193.

25. Yasmeen S, Cress R, Romano PS, et al, 2005 Thyroid cancer in pregnancy. Int J Gynaecol Obstet 91:15-20.
26. Imai Y, Yamakawa M, Matsuda M, Kasajima T, 1989 Endogenous sex hormone and estrogen binding activity in thyroid cancer. Histol Histopathol 4: 39-45.

27. Jaklic BR, Rushin J, Ghosh BC, 1995 Estrogen and progesterone receptors in thyroid lesions. Ann Surg Oncol 2: 429-434.

28. Yoshimura M, Hershman JM, 1995 Thyrotropic action of human chorionic gonadotropin. Thyroid 5: 425-434.

29. Younes MN, Yigitbasi OG, Park YW, et al, 2005 Antivascular therapy of human follicular thyroid cancer experimental bone metastasis by blockade of epidermal growth factor receptor and vascular growth factor receptor phosphorylation. Cancer Res 65: 4716-4727.

30. Turner HE, Harris AL, Melmed S, Wass JA, 2003 Angiogenesis in endocrine tumors. Endocr Rev 24: 600-632.

31. Segal K, Shpitzer T, Feinmesser M, Stern Y, Feinmesser R, 1996 Angiogenesis in follicular tumors of the thyroid. J Surg Oncol 63: 95-98.

32. Brecelj E, Frkovic Grazio S, Auersperg M, Bracko M, 2005 Prognostic value of E-cadherin expression in thyroid follicular carcinoma. Eur J Surg Oncol 31: 544-548.

33. Yamashita H, Noguchi Y, Noguchi S, et al, 2005 Significance of an insular component in follicular thyroid carcinoma with distant metastasis at initial presentation. Endocr Pathol 16: 41-48.

34. Falvo L, Catania A, D'Andrea V, et al, 2004 Prognostic factors of insular versus papillary/follicular thyroid carcinoma. Am Surg 70: 461-466.

35. D'Avanzo A, Ituarte P, Treseler P, et al, 2004 Prognostic scoring systems in patients with follicular thyroid cancer: a comparison of different staging systems in predicting the patient outcome. Thyroid 14: 453-458.

36. Haq M, Harmer C, 2005 Differentiated thyroid carcinoma with distant metastases at presentation: prognostic factors and outcome. Clin Endocrinol (Oxf) 63: 87-93.

37. Shoup M, Stojadinovic A, Nissan A, et al, 2003 Prognostic indicators of outcomes in patients with distant metastases from differentiated thyroid carcinoma. J Am Coll Surg 197: 191-197.

38. Brown AP, Greening WP, McCready VR, Shaw HJ, Harmer CL, 1984 Radioiodine treatment of metastatic thyroid carcinoma: the Royal Marsden Hospital experience. Br J Radiol 57: 323-327.

39. Dottorini ME, Lomuscio G, Mazzucchelli L, Vignati A, Colombo L, 1995 Assessment of female fertility and carcinogenesis after iodine-131 therapy for differentiated thyroid carcinoma. J Nucl Med 36: 21-27.

40. Hall P, Holm LE, Lundell G, Ruden BI, 1992 Tumors after radiotherapy for thyroid cancer. A case-control study within a cohort of thyroid cancer patients. Acta Oncol 31: 403-407.

41. de Vathaire F, Schlumberger M, Delisle MJ, et al, 1997 Leukaemias and cancers following iodine-131 administration for thyroid cancer. Br J Cancer 75: 734-739.

42. Rubino C, de Vathaire F, Dottorini ME, et al, 2003 Second primary malignancies in thyroid cancer patients. 
Br J Cancer 89: 1638-1644.

43. Rall JE, Alpers JB, Lewallen CG, et al, 1957 Radiation pneumonitis and fibrosis: a complication of radioiodine treatment of pulmonary metastases from cancer of the thyroid. J Clin Endocrinol Metab 17: 1263-1276.

44. Brierley J, Tsang R, Panzarella T, Bana N, 2005 Prognostic factors and the effect of treatment with radioactive iodine and external beam radiation on patients with differentiated thyroid cancer seen at a single institution over 40 years. Clin Endocrinol (Oxf) 63: 418-427.

45. Meadows KM, Amdur RJ, Morris CG, et al, 2006 External beam radiotherapy for differentiated thyroid cancer. Am J Otolaryngol 27: 24-28.

46. Casara D, Rubello D, Saladini G, et al, 1991 Distant metastases in differentiated thyroid cancer: long-term results of radioiodine treatment and statistical analysis of prognostic factors in 214 patients. Tumori 77: 432-436.

47. Proye CA, Dromer DH, Carnaille BM, et al, 1992 Is it still worthwhile to treat bone metastases from differentiated thyroid carcinoma with radioactive iodine? World J Surg 16:640-646. 